\title{
Decomposition of Polyethylene 2,6-Naphthalene Dicarboxylate to Constituent Monomers Using Supercritical Methanol
}

\author{
Takeshi Sako, Tsutomu Sugeta, Katsuto Otake, Satoshi Yoda, \\ Yoshihiro TaKebayashi, Izumi OKaJIMA, \\ and Chiyoshi KamIzawa
}

Department of Chemical Systems, National Institute of Materials and Chemical Research, Higashi 1-1, Tsukuba, Ibaraki 305-8565, Japan

(Received April 9, 1999)

KEY WORDS Chemical Recycling/Supercritical Methanol/Polyethylene 2,6-Naphthalene Dicarbox-
ylate

In recent years, much attention has been paid to new technologies for recycling of waste plastics into reusable resources using supercritical fluids, because the Container and Package Recycling Law was enacted in 1997 and extensive recycling of waste plastics began in Japan. In the previous work, we showed that polyethylene terephthalate (PET) was depolymerized rapidly into its constituent monomers and oligomer using supercritical methanol at $573 \mathrm{~K}$ and more than $8 \mathrm{MPa}$ for $30 \mathrm{~min}$ of the reaction time. ${ }^{1,2}$ Comparing with the conventional decomposition methods using a liquid solvent such as liquid methanol ${ }^{3}$ or liquid ethylene glycol ${ }^{4}$ along with zinc acetate as a catalyst at $435 \mathrm{~K}$ and $3-4 \mathrm{MPa}$, much higher reaction rate and complete decomposition were realized without any catalyst.

Polyethylene 2,6-naphthalene dicarboxylate (PEN) is expected as a PET alternative in near future, because PEN has superior physical and mechanical properties to PET in high glass temperature, low gas permeability and high resistance to solvents. ${ }^{5}$ However, no attempt for the chemical recycling was carried out owing to the large structural stability at molecular level. In this study, we investigated the possibility of the depolymerization of PEN to its constituent monomers and oligomer using supercritical methanol without any catalyst.

\section{EXPERIMENTAL}

Experimental apparatus and procedure were almost the same as the previous work except for the analytical method of the decomposition products. The product of the liquid and solid states was analyzed according to the procedure given in Figure 1. The product contained the monomers of dimethyl 2,6-naphthalene dicarboxylate (DMN) and ethylene glycol (EG), the oligomers, the unreacted PEN and methanol. Here the oligomer linking some units of the monomers was defined as a product which was hydrolyzed with $\mathrm{NaOH}$ aqueous solution to disodium 2,6-naphthalene dicarboxylate (NaNDA) and EG.

First, the decomposition product was filtered into a solid $\mathrm{A}$ and a liquid $\mathrm{A}$. The solid $\mathrm{A}$ contained the unreacted PEN, and a part of DMN monomer and oligomer which were not soluble in liquid A owing to the solubility limitation. The liquid A contained EG monomer, and a part of DMN monomer and oligomer. The solid A was analyzed as follows. After the removal of methanol by heating at $323 \mathrm{~K}$, the oligomer was decomposed with $2 \mathrm{~N} \mathrm{NaOH}$ solution to NaNDA and EG. The solution was filtered to a solid B and a liquid B. Chloroform was added into the solid B and then an undissolved solid D was separated from a liquid D by filtration. The solid D was the unreacted PEN and was weighed by a balance after drying at $323 \mathrm{~K}$. The liquid $\mathrm{D}$ dissolved DMN monomer and was analyzed with a gas chromatograph equipped with a FID detector (GC-FID). The liquid B contained NaNDA and EG from the oligomer decomposition. The EG was analyzed by GC-FID and the amount of NaNDA was determined by a liquid chromatograph (LC). Each component in the liquid $\mathrm{A}$ was analyzed in the same way as that in the solid A according to the procedure in Figure 1.

Finally the unreacted PEN was recovered as the solid $\mathrm{D}$, the DMN monomer as the liquids $\mathrm{A}$ and $\mathrm{D}$, the EG monomer as the liquid $\mathrm{A}$, the $\mathrm{DMN}$ component in the oligomer as the liquids $\mathrm{B}$ and $\mathrm{C}$, and the $\mathrm{EG}$ component in the oligomer as the liquid $\mathrm{B}$ and the difference of the amount of the EG in the liquid $\mathrm{A}$ from that in the liquid $\mathrm{A}^{\prime}$.

\section{RESULTS AND DISCUSSION}

The PEN was decomposed by supercritical methanol as follows:

$$
\text { (Ethylene glycol) }
$$

We evaluated the decomposition characteristics in terms of the PEN residue ratio and the product yields of DMN and EG given by

$\mathrm{PEN}$ residue ratio $(\%)=$

$$
\frac{\text { Grams of PEN after reaction }}{\text { Grams of charged PEN }} \times 100
$$




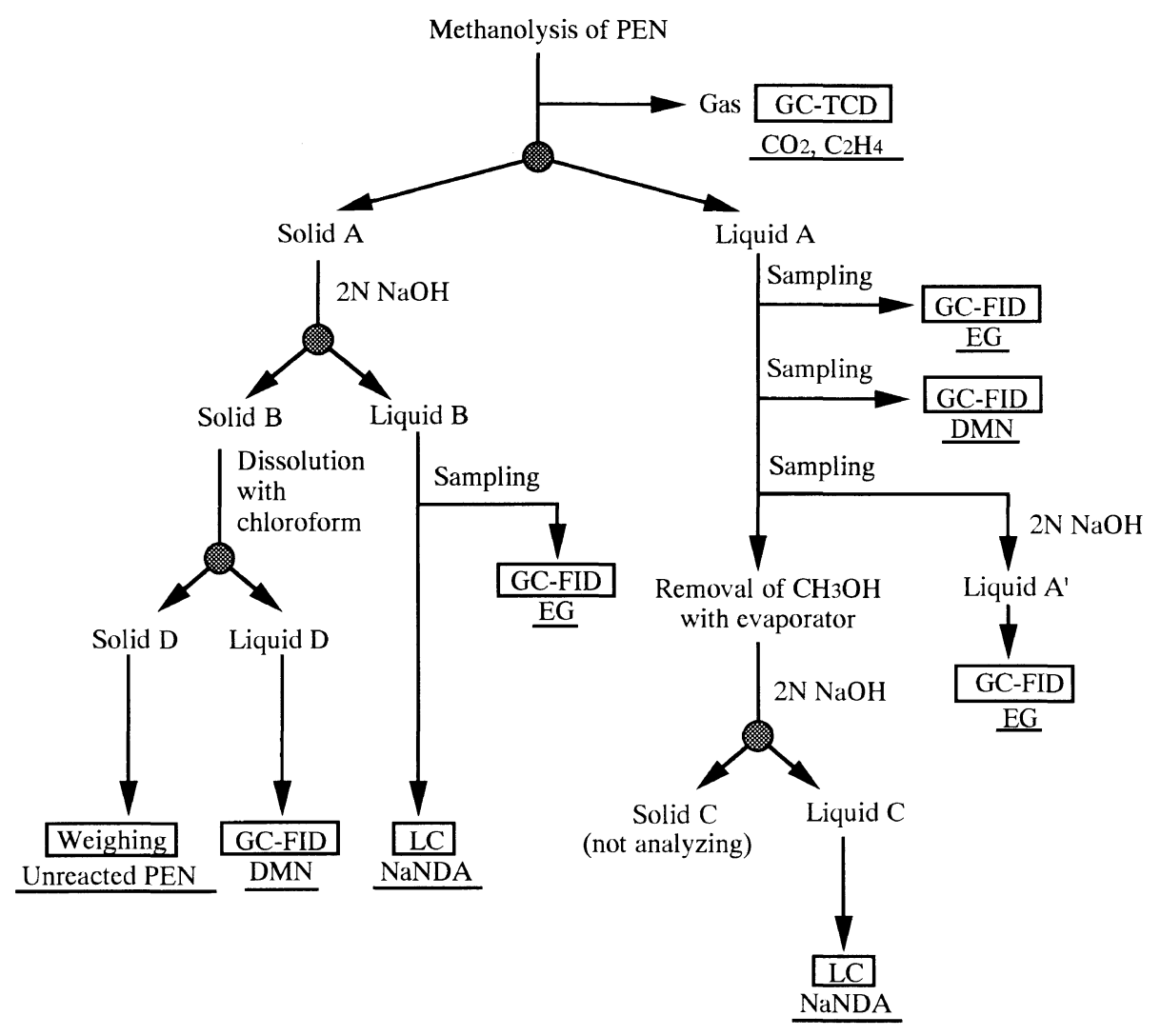

DMN : Dimethyl 2,6-naphthalene dicarboxylate

EG : Ethylene glycol

NaNDA: Disodium 2,6-naphthalene dicarboxylate

- : Filtration to separate liquid from solid

Figure 1. Analytical procedure of decomposition product of PEN.

Yield of DMN monomer $(\%)=$

$\frac{\text { Moles of produced DMN monomer } \times 12}{\text { Moles of repeating segment of } \mathrm{PEN} \times 14} \times 100$

Yield of EG monomer $(\%)=$

Moles of produced EG monomer $\times 2$

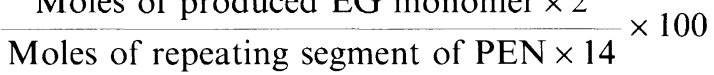

The yield of each monomer was defined based on the number of the carbon atoms in the repeating segment of the PEN and in the monomer. There are 14 carbon atoms in the PEN segment, 12 carbon atoms in the DMN monomer, and 2 carbon atoms in the EG monomer. When the PEN was decomposed to the monomers completely, the maximum yield of the monomers was $85.7 \%$ for DMN and $14.3 \%$ for $\mathrm{EG}$; the $\mathrm{PEN}$ residue ratio was $0 \%$; and then the $\mathrm{PEN}$ residue ratio $+\mathrm{DMN}$ monomer yield $+\mathrm{EG}$ monomer yield $=100 \%$. The yield of $\mathrm{DMN}$ or $\mathrm{EG}$ oligomer was defined by the equations similar to the monomers mentioned above, where the moles of a specific monomer produced were replaced by the moles of a specific component obtained from the decomposition of the oligomer.

In this experiment, the amount of gases produced was negligibly small. This was because the use of supercritical methanol assured a relatively low decomposition tem- perature of $623 \mathrm{~K}$, thus suppressing the secondary decomposition of the recovered monomers.

Figure 2 shows the influence of the reaction pressure on the product yields under the conditions of a reaction temperature of $623 \mathrm{~K}$ and a reaction time of $30 \mathrm{~min}$, where the yield of the decomposition product in the $y$-axis was the sum of the yield of the monomer and the corresponding component in the oligomer. About $5 \%$ of the PEN remained undecomposed at around $5 \mathrm{MPa}$ and, as the pressure increased, the decomposition was accelerated and the PEN was decomposed completely at more than $10 \mathrm{MPa}$. In addition, $100 \%$ of the DMN and EG were recovered in the form of the monomers and oligomers. In this experiment, most oligomer was a $1: 1$ type composed of DMN and EG: $\mathrm{H}_{3} \mathrm{COOC}-\mathrm{C}_{10} \mathrm{H}_{6}$ $\mathrm{COOCH}_{2} \mathrm{CH}_{2} \mathrm{OH}$. The oligomer could be recycled as a raw material of the PEN, because it had almost the same reactivity as the monomers in polymerization and could dissolve in methanol like the monomers. Next, we prolonged the reaction time to $60 \mathrm{~min}$ while leaving the reaction temperature unchanged at $623 \mathrm{~K}$, and examined the pressure dependence of the product yields. The results are shown in Figure 3 . When the reaction time was extended, there was no unreacted PEN except in the low pressure region below $5 \mathrm{MPa}$.

We investigated the ratio of the monomer to the decomposition product for DMN under different reac- 


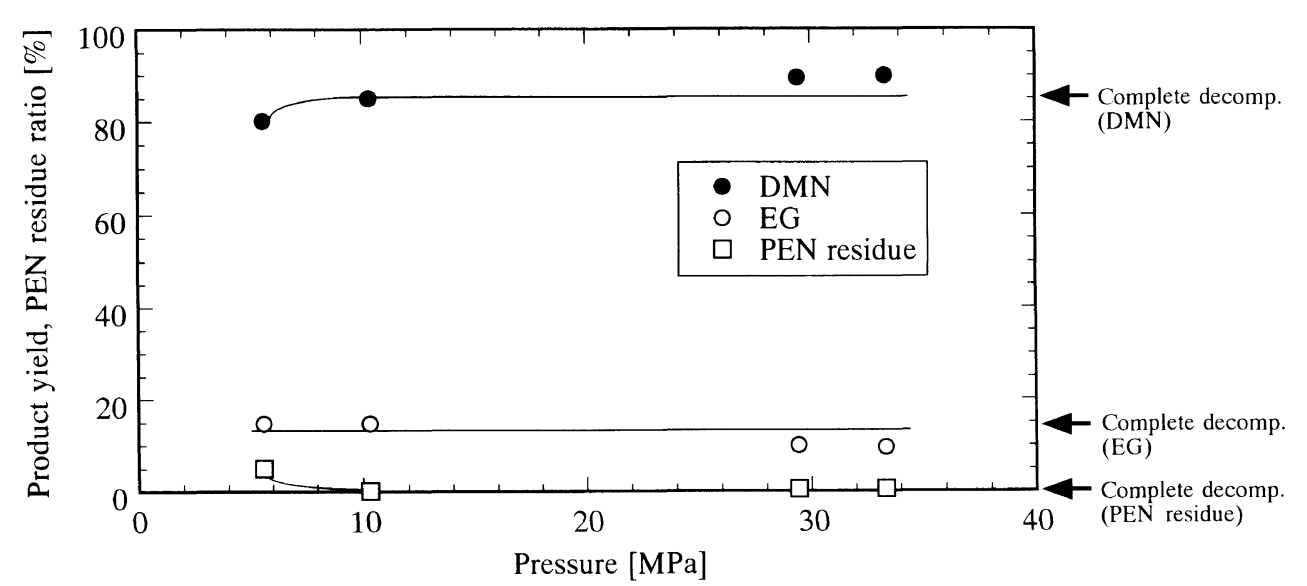

Figure 2. Influence of pressure on product yields of $P E N$ decomposition (temperature $=623 \mathrm{~K}$; reaction time $=30 \mathrm{~min}$ ).

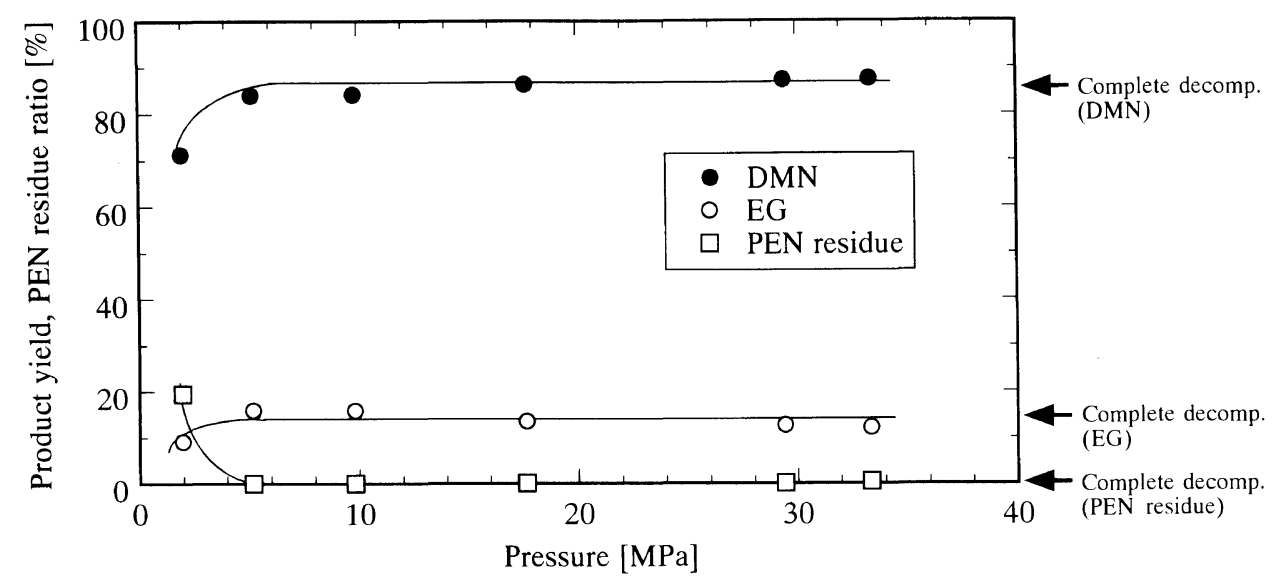

Figure 3. Influence of pressure on product yields of $P E N$ decomposition (temperature $=623 \mathrm{~K}$; reaction time $=60 \mathrm{~min}$ ).

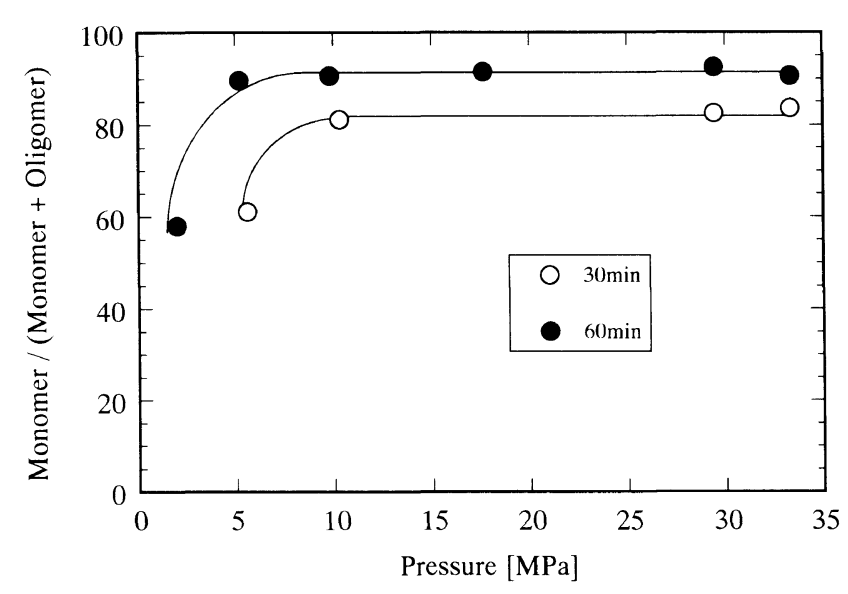

Figure 4. Pressure dependence of monomer ratio of DMN component in PEN at $623 \mathrm{~K}$. tion time and pressure conditions. The ratio of the DMN monomer increased with the pressure steeply in the low pressure region and was almost constant at $81-84 \%$ for $30 \mathrm{~min}$ of the reaction time and at $90-93 \%$ for $60 \mathrm{~min}$. Severe decomposition conditions, for example a high temperature, a high pressure and a long reaction time, were preferable in order to obtain large amount of monomers, but the complete conversion to monomers might be difficult owing to the reversible reaction between depolymerization and polymerization of the PEN.

\section{REFERENCES}

1. T. Sako, T. Sugeta, K. Otake, N. Nakazawa, M. Sato, K. Namiki, and M. Tsugumi, J. Chem. Eng. Japan, 30, 342 (1997).

2. T. Sako, T. Sugeta, K. Otake, Y. Takebayashi, C. Kamizawa, M. Tsugumi, and M. Hongo, Kobunshi Ronbunshu, 55, 685(1998).

3. H. Grunschke, W. Hammerschick, and B. Naucheim, US Patent 3403115 (1968).

4. S. Baliga and W. T. Wong, J. Polym. Sci., Part A, Polym. Chem., 27, 2071 (1989).

5. S. Irie, Plastics (Japanese J.), 50, 61 (1999). 